\title{
Theme development in qualitative content analysis and thematic analysis
}

\author{
Mojtaba Vaismoradi ${ }^{1}$, Jacqueline Jones ${ }^{2}$, Hannele Turunen ${ }^{3}$, Sherrill Snelgrove ${ }^{* 4}$ \\ ${ }^{1}$ Faculty of Professional Studies, Nord University, Bodø, Norway \\ ${ }^{2}$ College of Nursing, University of Colorado, Aurora, CO, United States \\ ${ }^{3}$ Department of Nursing Science, Faculty of Health Sciences, Kuopio Campus, University of Eastern Finland, Kuopio, Finland \\ ${ }^{4}$ College of Human and Health Sciences, Swansea University, Wales, United Kingdom
}

Received: November 27, 2015

DOI: $10.5430 /$ jnep.v6n5p100
Accepted: January 10, $2016 \quad$ Online Published: January 15, 2016

URL: http://dx.doi.org/10.5430/jnep.v6n5p100

\begin{abstract}
Sufficient knowledge is available about the definition, details and differences of qualitative content and thematic analysis as two approaches of qualitative descriptive research. However, identifying the main features of theme as the data analysis product and the method of its development remain unclear. The purpose of this study was to describe the meaning of theme and offer a method on theme construction that can be used by qualitative content analysis and thematic analysis researchers in line with the underpinning specific approach to data analysis. This methodological paper comprises an analytical overview of qualitative descriptive research products and the meaning of theme. Also, our practical experiences of qualitative analysis supported by relevant published literature informed the generation of a stage like model of theme construction for qualitative content analysis and thematic analysis. This paper comprises: (i) analytical importance of theme, (ii) meaning of theme, (iii) meaning of category, (iv) theme and category in terms of level of content, and (v) theme development. This paper offers a conceptual clarification and a pragmatic step by step method of theme development that has the capacity of assisting nurse researchers understand how theme is developed. As nursing is a pragmatic discipline, nurse researchers have tried to develop practical findings and devise some way to "do something" with findings to enhance the action and impact of nursing. The application of a precise method of theme development for qualitative descriptive data analysis suggested in this paper helps yield meaningful, credible and practical results for nursing.
\end{abstract}

Key Words: Content analysis, Qualitative analysis, Research, Theme, Thematic analysis

\section{INTRODUCTION}

Qualitative research as a group of approaches for the collection and analysis of data aims to provide an in-depth, socio-contextual and detailed description and interpretation of the research topic. ${ }^{[1,2]}$

It covers a broad range of approaches with a wide variation in concepts, assumptions and analytic rules. Despite this variation all qualitative methodologies contribute to description and interpretation of complex phenomena, developing and revising understanding, rather than purely verifying earlier conclusions of theories. ${ }^{[3,4]}$

Qualitative content analysis and thematic analysis are classified under the qualitative descriptive design. They are sets of techniques used to analyse textual data and elucidate theme. ${ }^{[5]}$ Their key characteristic is the systematic process of coding, examining of meaning and provision of a description

\footnotetext{
*Correspondence: Sherrill Snelgrove; Email: S.R.Snelgrove@ Swansea.ac.uk; Address: College of Human and Health Sciences, Swansea University,
} Wales, United Kingdom. 
of the social reality through the creation of theme. ${ }^{[6,7]}$

The description and interpretation of participants' perspectives are features of all qualitative approaches. However, some researchers believe that the application of qualitative content analysis and thematic analysis is suitable for those who want to employ a lower level of inference interpretation, rather than a more abstract interpretation. ${ }^{[2,8]}$ In other words, they focus on the explicit description of the content of communication with a limited reflection on its implicit meaning. ${ }^{[9,10]}$

\section{Significance OF THEME IN QUALITA- TIVE CONTENT AND THEMATIC ANALYSIS}

"Theme" is the main product of data analysis that yields practical results in the field of study. ${ }^{[11,12]}$ The definition, similarities and differences of qualitative content analysis and thematic analysis have been defined. According to Vaismoradi et al.'s study (2013), there are many similarities between qualitative content analysis and thematic analysis, for instance cutting across data, philosophical background, attention to both description and interpretation in data analysis, consideration of context of data, and searching for themes. While the thematic analysis researcher considers both latent content as theme and manifest content as category in data analysis, the content analyst chooses between them before proceeding to the higher levels of data analysis. Coding, collecting codes under potential subthemes or themes, and comparing the emerged coding's clusters together and in relation to the entire data set comprise the main components of data analysis in both methods. The same set of analytical interventions used in qualitative content analysis is applied in thematic analysis. In addition, in both methods, the creativity of the researcher is an integral part of the analysis and in presenting the result in terms of a story line. ${ }^{[8]}$

The literature that outlines the meaning of theme and suggests a step by step process of the development of theme is insufficient. Moreover, a considerable diversity and lack of details on the identification of theme in the literature has often compounded the issue of development of theme. ${ }^{[11,13,14]}$ Therefore, questions surrounding the process of theme construction in qualitative content analysis and thematic analysis are addressed in this paper to help with an analytical clarification, and to increase rigour and acceptability of data analysis.

The aim of this methodological paper is to describe the meaning of theme and offer a method on theme construction that can be used by qualitative content analysis and thematic analysis researchers notwithstanding the underpinning specific approach to data analysis. This methodological paper Published by Sciedu Press comprises an analytical overview of qualitative descriptive research products and the meaning of theme. Also, our practical experiences of qualitative analysis informed the suggestion of a development process for theme in qualitative content analysis and thematic analysis supported by selected international literature.

To achieve the aim of this paper, we have organised our findings accordingly: (i) analytical importance of theme, (ii) meaning of theme, (iii) meaning of category, (iv) theme and category in terms of level of content, and (v) theme development.

\section{AnAlytical importance OF THEME}

A central issue in the analysis is that the research participants' subjective meanings and social reality are appropriately conveyed in the research report. ${ }^{[15,16]}$ Data are not simply containers of meaning. A text may involve multiple meanings and their identification requires researcher's efforts in the process of analysis. ${ }^{[11,12]}$ Meanings are conveyed in terms of themes and their related subdivisions as subthemes, though some variations are available in the use of the terms of "category" and "theme". ${ }^{[11,17,18]}$ Therefore, the description of the process of theme development depends on the definition and clarification of these terms described as follows.

\section{MEANING OF THEME}

Theme is used as attribute, descriptor, element, and concept. ${ }^{[9]}$ As an implicit topic that organizes a group of repeating ideas, it enables researchers to answer the study question. ${ }^{[19]}$ It contains codes that have a common point of reference and has a high degree of generality that unifies ideas regarding the subject of inquiry. ${ }^{[3,20]}$

It is considered a thread of underlying meaning implicitly discovered at the interpretative level and elements of subjective understandings of participants. ${ }^{[19,21,22]}$

Each theme may have some subthemes as subdivisions to obtain a comprehensive view of data and uncovers a pattern in the participants' account. ${ }^{[23,24]}$

Too descriptive nature of themes developed by some qualitative researchers due to premature closure of data analysis, and ambiguities with regard to the process of theme development make it difficult to judge the quality of analytical process and its discrimination from category development. In addition, category and theme are sometimes used interchangeably that results in a lack of cohesion between the method of data analysis and the result. ${ }^{[25]}$ Therefore, at the beginning of description of process of theme development, there is a need to describe the meaning of category and differentiate it from theme in terms of level of depth and abstraction. 


\section{MeAning OF CATEgORY}

Category refers to the descriptive level of text and is explicit manifestation of the participants' account. ${ }^{[26]}$ Categories are descriptors of themes. ${ }^{[1,27]}$ Similar to theme, the meaning of category is attributed by the researcher and it may consist of subcategories that identify the meaning of category. ${ }^{[28]}$ Category is the primary product of analytical process, has a descriptive identity and is mainly used at the beginning of the theme development process to classify findings. Researchers develop category at the beginning of data analysis process to enter the abstraction process. Category development helps with the provision of details for analytical theme development. Constas (1992) has outlined a process for categorization that is consisted of three components: (i) origination, (ii) verification, and (iii) nomination. ${ }^{[28]}$ A summary of details of each component has been presented in Table 1 .

Table 1. A summary of details of the categorization process suggested by Constas (1992) ${ }^{[28]}$

\begin{tabular}{|c|c|}
\hline Components & Description \\
\hline Origination & $\begin{array}{l}\text { Using participants as a point of origination means that the participants can identify categories, as opposed to a researcher } \\
\text { identifying categories; } \\
\text { Using the investigator as a point of origination, categories are developed based on the personal interests, views, or } \\
\text { intellectual constructions of the researcher; } \\
\text { The researcher can refer to research or published works in the relevant area and derive categories from statements or } \\
\text { conclusions found in the literature of other researchers who investigated a similar phenomenon; } \\
\text { In the interpretative approach, as a distinct point of origination, interpretative categories have a more general variety in that } \\
\text { they are not directly related to the phenomena under investigation, but are more related to the method of analysis. }\end{array}$ \\
\hline Verification & $\begin{array}{l}\text { It is used to support the creation and application of categories in a given study; } \\
\text { It is consisted of sources of external (utilizing a panel of experts outside of the study to verify and substantiate categories), } \\
\text { rational (relying on relies on logic and reasoning), referential (utilizing existing research findings or theoretical arguments } \\
\text { to justify categories), empirical (relying on internal data and without reference to other studies to examine the coverage and } \\
\text { distinctiveness reflected by categories), technical (borrowing procedures, or at least language, from the quantitative } \\
\text { orientation), and participative (providing participants the opportunity to review and possibly modify categories). }\end{array}$ \\
\hline Nomination & $\begin{array}{l}\text { It concerns with naming categories; } \\
\text { The labels may be identical to those used under the origination component; } \\
\text { Participants can be a source of labelling; } \\
\text { Category names can be derived from existing theories and body of literature; } \\
\text { Labels can be derived from interpretative orientation. }\end{array}$ \\
\hline
\end{tabular}

\section{THEME AND CATEGORY IN TERMS OF LEVEL OF CONTENT}

Theme refers to a more implicit and abstract level, which requires interpretation. ${ }^{[29,30]}$ Category refers to explicit content of text and is a simple description of the participants' accounts. ${ }^{[31]}$ When researchers raise the participant's perspective to an abstract level of conceptualization and seek the underlying meaning in the participants' words, implicit meaning or theme is emerged. ${ }^{[32,33]}$ In other words, the purpose of theme is to elicit the essence of the participant's experiences. ${ }^{[25]}$

A category is an idea that is directly expressed in the text, ${ }^{[34]}$ but a theme is more than a category. The former is more general and abstract and has intellectual and affective content depending on the interpretation of the researcher. It is through the development of theme that category is given depth of meaning, ${ }^{[11]}$ thus its development has a priority to the development of category.

It is noted that categories, and subthemes are all relate to the path in which a researcher follow to reach to the most abstract analysis product as theme. Category is the higher order abstraction that groups related explicit concepts in the text, but "subtheme exists underneath the umbrella of a theme. Sub-theme shares the same central organising concept as the theme, but focuses on one notable specific element. It is through naming and analysing a specific subtheme that aspect of the theme becomes particularly salient". ${ }^{[35]}$

In line with the aim of this paper, the next section specifies the process of theme development based on our experiences of qualitative analysis and supported by relevant literature.

\section{THEME DEVELOPMENT}

A broad interest has been shown in recent years in the process of data analysis, but a detailed description of how researchers identify theme is under-reported. A probable reason is that in addition to empiricism, the way to find theme involves intuition that is difficult to be described. Although some suggested techniques are shown to be effective under some conditions, their nature and the way in which they are gener-

ISSN 1925-4040 E-ISSN 1925-4059 
ated varies between different qualitative approaches. More importantly there is little practical explanation about how theme is developed.

The qualitative analysis process is cyclic without finite interpretation, and requires researchers to return repeatedly to data and the coding process throughout the analysis process. The stage like and reiterative method of theme development suggested in this paper can be applied across approaches to facilitate the production of high quality findings.

We propose four phases of theme development: "initialization", "construction", "rectification", and "finalization". Each phase consists of some stages that are described as follow (see Table 2).

Table 2. Phases and stages of theme development in qualitative content and thematic analysis

\begin{tabular}{ll}
\hline Phases & Stages \\
\hline \multirow{3}{*}{ Initialization } & Reading transcriptions and highlighting meaning units; \\
& Coding and looking for abstractions in participants' accounts; \\
& Writing reflective notes. \\
& Classifying; \\
& Comparing; \\
& Labelling; \\
Construction & Translating \& transliterating; \\
& Defining \& describing. \\
& Immersion and distancing; \\
& Relating themes to established knowledge; \\
Rectification & Stabilizing. \\
& Developing the story line \\
\hline
\end{tabular}

\subsection{Initialization phase}

Materials for data analysis consist of all sorts of data that can be transformed to the textual format including interview transcripts, participant observation field notes, journals, documents, literature, artefacts, photographs, video, websites, e-mail correspondence, and so on. Through reading and rereading transcripts, researchers reach an overall understanding of data and also the main issues in the phenomenon under study. This understanding prepares them to focus on the most important constructs recognized and presented in data. In this primary step of data analysis, researchers transcribe the data, take notes and read them several times so as to describe the trend of the participants' perspectives that can be traced back using direct quotations from the transcription.

This initial phase consists of three stages: "reading transcriptions and highlighting meaning units", "coding and looking for abstractions in participants' accounts", and "writing reflective notes".

\subsubsection{Reading transcriptions and highlighting meaning units}

The ability to generate ideas and make sense of data depends on researchers' closeness to data through immersion. Immersion is achieved through careful reading of transcripts, and listing meaningful, recurrent ideas and key issues in data. Recurring items of interest such as events or comments that are unusual, noteworthy or contradictory from researchers' perspectives are highlighted. Next, they look for ideas in the data to recognise explicit and implicit ideas in the transcription based on their own judgement. They must, however, be careful not to be too much influenced by their own stance as they might risk losing important data. ${ }^{[19,36]}$ Remaining close and focused on the data, and considering possible meanings and how they are fitted together provide clues for theme development. ${ }^{[37]}$

\subsubsection{Coding and looking for abstractions in participants' accounts}

Coding as the process of data reduction is an element of data organization in most qualitative approaches. ${ }^{[11,38]}$ To facilitate coding, different types of codes are recognized in qualitative content analysis and thematic analysis (see Table 3): "Conceptual code" identifies key elements, domains and dimensions of the study phenomenon; "relationship code" identifies links between elements, domains and dimensions; "participant perspective code" identifies the participant's positive, negative, or indifference comments about a particular experience; "participant characteristic code" and "setting code" show the general characteristics of participants and the place in which the phenomenon has happened, respectively. ${ }^{[3]}$ Such a classification not only helps researchers organize codes, but also enables detailed comparison and classification prior to the subsequent analytical steps. 
Table 3. Examples of different types of coding

\begin{tabular}{|c|c|c|c|}
\hline Types of codes & Example & Extracted code & $\begin{array}{l}\text { Principles of coding according to } \\
\text { Polit \& Beck (2010) }\end{array}$ \\
\hline $\begin{array}{l}\text { Conceptual } \\
\text { code }\end{array}$ & $\begin{array}{l}\text { I knew only what the name of the drug } \\
\text { was and which diseases it would treat, } \\
\text { but I knew nothing about how it should } \\
\text { be administered in practice. }\end{array}$ & $\begin{array}{l}\text { Lack of knowledge on drugs' } \\
\text { practical administration }\end{array}$ & \multirow{5}{*}{$\begin{array}{l}\text { In line with the reductionist nature } \\
\text { of qualitative data management, the } \\
\text { researcher converts large masses of } \\
\text { data into smaller, more manageable } \\
\text { segments as codes; } \\
\text { Coding leads to breaking down } \\
\text { data into incidents and examining } \\
\text { their similarities and differences; } \\
\text { The coding process is a cyclic } \\
\text { process without a finite } \\
\text { interpretation and the researcher's } \\
\text { efforts determine the level of } \\
\text { coding abstraction; } \\
\text { Investigator triangulation as } \\
\text { independent coding and analysis of } \\
\text { some of the data by two or more } \\
\text { researchers is an appropriate } \\
\text { method for enhancing quality of the } \\
\text { coding process. }\end{array}$} \\
\hline $\begin{array}{l}\text { Relationship } \\
\text { code }\end{array}$ & $\begin{array}{l}\text { Instructor's presence with students in } \\
\text { clinical placement is necessary to make } \\
\text { the collaboration of students in } \\
\text { medication administration in clinical } \\
\text { practice possible. }\end{array}$ & $\begin{array}{l}\text { Necessity of instructor's } \\
\text { supervision in medication } \\
\text { education }\end{array}$ & \\
\hline $\begin{array}{l}\text { Participant } \\
\text { perspective } \\
\text { code }\end{array}$ & $\begin{array}{l}\text { I believe that patients are fully able to } \\
\text { check the accuracy of the nurse's } \\
\text { medication administration. }\end{array}$ & $\begin{array}{l}\text { Positive attitude towards } \\
\text { patient's participation }\end{array}$ & \\
\hline $\begin{array}{l}\text { Participant } \\
\text { characteristic } \\
\text { code }\end{array}$ & $\begin{array}{l}\text { As a final year and senior nursing } \\
\text { student, I liked helping the nurse to } \\
\text { administer drugs, but she did not allow } \\
\text { me to work with her. }\end{array}$ & $\begin{array}{l}\text { Senior student's eagerness to } \\
\text { collaborate }\end{array}$ & \\
\hline Setting code & $\begin{array}{l}\text { In critical care settings, I have been } \\
\text { provided with more chances to practice } \\
\text { medication administration. }\end{array}$ & $\begin{array}{l}\text { Critical care settings' } \\
\text { cooperation in medication } \\
\text { education }\end{array}$ & \\
\hline
\end{tabular}

Coding reduces the amount of raw data to that which is relevant to the research question, breaks the data down to manageable sections, and takes researchers through the transformation of raw data to higher-level insights or abstractions as the development of theme. ${ }^{[5,39,40]}$ Researchers recognise coding as one level of abstraction, because they use intuition to extract the meaning of data and present description and interpretation at a higher logical level. ${ }^{[22,41]}$ We believe that to increase the rigour of qualitative content analysis and thematic analysis, ambiguities surrounding coding should be reduced through illustrating progression from concrete to abstraction. During the abstraction process, according to researchers' judgment, the transformation process from concrete to abstract is conducted in such a way that each step has a higher level of "generality" (see Figure 1). At a practical level, concurrently with the initial data collection, after reaching a general understanding of the content and context of the phenomenon under study, the coding process is started to reveal explicit and implicit meanings. ${ }^{[3,38]}$ Finding the appropriate answer to the research question depends on selecting the relevant section of the transcription for coding and choosing an appropriately sized section so as to prevent losing subtleties in the meaning. Next, researchers address important codes for further consideration, although withholding any final decision until the latter steps of data analysis. ${ }^{[42-44]}$ Beginning coding with a specific focus or narrower definition hinders discerning codes or obscures the ability to recognise themes. ${ }^{[5]}$

\begin{tabular}{|c|c|}
\hline Abstraction level & Example of coding \\
\hline & Collaboration \\
Developing a team framework \\
Working together to reach the same aim \\
Taking the responsibility of doing a task collectively \\
Relying on each other commitments and efforts to take a united action \\
Coming together to resolve an issue related to all individuals using the power of collection
\end{tabular}

Figure 1. An example of abstraction for coding in qualitative content and thematic analysis 


\subsubsection{Writing reflective notes}

Research notes map the analytical process and uncover researchers' perspectives and tighten data collection. ${ }^{[36,45]} \mathrm{Al}-$ though the importance of research notes in qualitative content analysis and thematic analysis has remained relatively unexplored, it helps identify the audit trail to substantiate trustworthiness. ${ }^{[46,47]}$ Notes facilitate reflexivity and provide researchers with an opportunity to remember, question, and make meaning of data. They also allow researchers to remain faithful to participants' perspectives and improve the validity of theme development. ${ }^{[46,48]}$ While the preferences and abilities of researchers and the focus of the research determine the content of notes, notations of features of data such as pauses and repetitions are required to explore ideas behind communication. ${ }^{[19,46]}$ Moreover, deepening researchers' understanding of their fieldwork, the interpretation of data, and their comparison with related codes and segments of transcriptions are pivotal aspects of research notes. Generally, the collected raw data and the interpretation made by researchers are divided during writing notes. ${ }^{[45,48,49]}$

\subsection{Construction phase}

Briefly, in this phase of data analysis, researchers reflect on the process of organizing codes and compare them in terms of similarities and differences to assign a place to each cluster of codes in relation to the research question. Considering the rule of "comprehensiveness and mutually exclusiveness" of codes in each cluster, researchers discover the diversities between codes in terms of meaning. A label is assigned to each cluster covering similar codes. The definition, translation and description of the label are cornerstones by which the level of abstraction of data analysis is improved and theme is created. This phase consists of five stages: "classifying", "comparing", "labelling", "translating and transliterating" and "defining and describing" is explained.

\subsubsection{Classifying}

The basic premise of classifying codes is "typification". It is the process of grouping a large range of codes under a "typical" similarity that can be generalized to them all despite their variety of details and subtleties. Typification is the result of researchers' creativity during the organization of codes through giving a common meaning to a group of codes with various features. According to the principle of mutual exclusiveness, if a code has attributes of more than one classification group, it is assigned only to one that best fits. $^{[12,43]}$

Therefore, the theme becomes the recurrent unifying idea that characterizes the experiences of participants by a holistic insight from the whole of data. ${ }^{[3,13,50]}$

Published by Sciedu Press

\subsubsection{Comparing}

Comparison as an iterative cyclical process is carried out within a single piece of data or across data. Researchers revise codes, detect negative cases and connect codes together to delineate themes. ${ }^{[51,52]}$ Comparison creates the potential for generating and suggesting plausible themes. ${ }^{[53]}$

If a group of codes are repeated in a patterned way and in multiple situations, they have potential to become a theme. ${ }^{[20,54]}$ Comparison has the capacity to reveal the link between codes and nominate themes using researchers' intellectual judgment. Testing propositions and asking questions of similarities and differences between codes enable the detection of theme. The more the same code occurs in a text, the more likely it can be considered to be a theme, but the constitution of a theme through the frequency of repetitions has to be decided by researchers' judgment. ${ }^{[1,19]}$ While the importance of a theme can be influenced by its level of frequency throughout data, it should rather capture something important in relation to the overall research question.

Through close reading, researchers scrutinize data to ensure that they have gone beyond what they were looking for at the beginning of the analysis process and reach higher levels of abstraction. ${ }^{[9,19]}$

\subsubsection{Labelling}

"Label" as a conceptual word captures something important about what is presented by the participant. As an easily understood word or phrase, label is taken from the content of the transcript. Researchers need to sort codes into piles of similar meaning and find labels that give sense of the main ideas developing from them. Knowledge of vocabulary and words help with labelling of theme as label is usually derived from conversation topics, meanings, feelings, and proverbs found or generated by researchers during reading transcriptions. ${ }^{[23]}$ Sandelowski and Leeman (2012) believe that a phrase or sentence is much preferred than a word for a label as it captures complete ideas. ${ }^{[13]}$ If the chosen phrase needs considerable explanation to convey the meaning to the reader, it is not a suitable label. ${ }^{[17]}$

\subsubsection{Translating and transliterating}

The continuation of the coding process in qualitative research entails identifying and describing theme through language use. ${ }^{[55]}$ During labelling, researchers produce an understanding of codes by reference to their own understanding of concepts and experiences. This makes it difficult to judge of the quality of the label for a theme by readers as no one can trace back the changes in meaning of label in the context of translation. ${ }^{[56]}$

Especially when a label is required to be reciprocally trans- 
lated for the aim of publication, the complexity of meaning and the influence of the grammatical style in one language when no obvious equivalent phrase exists in another language may impact the quality of abstraction of theme. Language proficiencies help present participants' beliefs, words and behaviours and enhance the literacy and eloquence of label of theme. ${ }^{[38,57]}$

In practice, using two bilingual translators to translate theme into the target language and having a bilingual person to back-translate it into the source language, using a language expert panel to resolve epistemological issues, and the preparation of a translation guide help with the preservation of abstraction and the meaning of theme. ${ }^{[58,59]}$ "Transliteration" is applied when during translation no immediate meaning is found in the target language. It is the process of paraphrasing, replacing or complementing the meanings of words in one language with the meanings of another. ${ }^{[60]}$

\subsubsection{Defining and describing}

Qualitative content analysis and thematic analysis researchers are required to describe how they have identified and abstracted themes during data analysis beyond stating that they have been developed through reading and immersion in data. If the theme is identical to those already established and the label is not identical to that already available in the literature, researchers need to describe the theme including providing a comparative analysis of how it differs from the previously established one. The steps taken to define a theme should include a detailed and comprehensive report of processes and how the analysis process has progressed step by step. Any theme definition encapsulates the essences of what each theme is about and signals what aspects of data each theme captures. It encompasses the description of how well the theme fits into the whole data in relation to the research question. ${ }^{[61,62]}$ Drawing maps and charts for the description of theme helps understand the nature of the study phenomenon, create typologies and find associations between themes as requirements to reach their analytical interpretation. ${ }^{[63,64]}$

\subsection{Rectification phase}

In this phase, theme is on the verge of full development, but researchers need take stock, continue to reappraise the analysis process and "distance" themselves from the data for a period of time so as to increase their sensitivity and reduce any premature and incomplete data analysis. This phase also may be termed "verification" as the process of checking and confirming, ensures a relative certainty about developed themes. The verification process illuminates some obscured aspects of data analysis during the transformation of data to themes. This phase consists of three stages: "immersion and distancing", "relating themes to established knowledge", and "stabilizing".

\subsubsection{Immersion and distancing}

Paradoxically, researchers need to both immerse themselves in the data and conversely distance themselves from the data so as to reveal theme, and to assess and examine the accuracy of the coding process. Maintaining closeness to data is required for a valid representation of participants' views. However, it may prevent researchers from taking a critical approach towards data analysis and hinders their ability to be rigorous in data analysis. This analytical tension can be allayed through distancing oneself from data for a period of time and/or reading the analysis from an "outsider perspective". This can facilitate and improve data analysis by allowing the researcher to maintain a sense of self-criticism of the analysis process conducted by himself/herself and look at the phenomenon from a new angle. ${ }^{[43,65,66]}$

Distancing from data is in line with the common notion of qualitative analysis as a self-correcting and cyclic process that encourages researchers to move back and forth between the study method and findings to ensure congruence between the focus of study, and data collection strategies and analysis. ${ }^{[52]}$ This may be a "lone endeavour" process, but a group discussion between researchers help explore various interpretations of the findings and give evidence of confirmability of theme.

\subsubsection{Relating themes to established knowledge}

While engagement with existing literature prior to data collection is characteristic of most qualitative methods, it is strongly suggested that an in-depth literature review is postponed until after most data collection is completed to prevent introducing bias and perceived notions. It allows themes to emerge naturally from the empirical data during analysis, uninhibited by extant theoretical frameworks and associated hypotheses. ${ }^{[67,68]}$ Therefore, researchers are encouraged to keep the literature in abeyance so as to conduct inductive analysis and develop theme, though this might be difficult for those who have theoretical knowledge of the study phenomenon. It is believed that a priori theorizing may affect researchers' ability to innovatively develop theme. ${ }^{[69]}$ However, the benefits of a literature review can outweigh threats to the inductive theme development as it allows researchers to make inferences from data beyond what has been made. Once theme is developed and the literature is studied, researchers can claim that they are ready to formulate theme statements, link themes into theoretical models to develop the study's story line. ${ }^{[19,23]}$ 


\subsubsection{Stabilizing}

A common flaw in qualitative content analysis and thematic analysis is where researchers offer a list of themes and their related subthemes without showing their connections to each other or using them to explain the phenomenon under study. Subthemes unlike themes consist of summaries and examples drawn from participants' accounts related to elements that build themes. The meaning of themes and the quality of their saturation can be found in subthemes. ${ }^{[32,55]}$

In stabilizing stage, themes and their variations are described, because the list of themes and subthemes alone without integration details has little analytical value. Researchers and readers may not share the same interpretation with regard to developed themes and subthemes. ${ }^{[9,70]}$ To enhance transparency and truthfulness, and facilitate transferability of findings to readers, attention is given to data saturation, description of the original context of data, and provision of material for reflection on data analysis in the appendices of the study report. ${ }^{[70,71]}$

\subsection{Finalization phase}

In this last phase of theme development, a narration developed by researchers as a written commentary describes and connects various themes, and answers the study question. The narration encompasses a "story line" that gives a holistic view on the study phenomenon. While the process of theme development in qualitative research is hardly finite, the story line is a helpful tool to convince both researchers and readers about the possible theoretical data saturation as the conventional principle of finalizing data collection and analysis. Creating a "story line" provides an opportunity to review the whole process of data analysis, promotes further ideas and collects even more data to improve saturation of theme. Therefore, this phase consists of the stage of "developing the story line".

\section{Developing the story line}

Any judgment of the validity of developed theme depends on themes' adequacy in portraying the "story line" developed based on participants' accounts. This is researchers' creativity to depict themes through the presentation of a story that is psychologically, culturally, and socially innovative. ${ }^{[36,42]}$ It aims to present the narrative and create a coherent story in which themes are described and connected. ${ }^{[72]}$ This typically involves choosing, chronicling, and ordering findings to produce an account of data. The nature of a story line may vary from a simple description to more interpretive and higher level abstraction of themes. ${ }^{[59]}$ How one moves from raw data towards a coherent and plausible story is based on the whole of data rather than isolated parts of data.

Published by Sciedu Press
According to Birks et al. (2009), the four main principles guiding the formation of participants' stories are "theoretical precedence" or writing the story in a manner of connecting themes and subthemes with their precedential relationships; "variation" as accounting for every individual case specifically; "limited gaps" as identifying and removing holes, gaps and inconsistencies; and "the use of evidence and appropriate style" as being creative while remaining faithful to data. ${ }^{[73]}$

It is suggested that researchers ultimately link their story line to the literature around which the content of themes in the study revolves to show how the study phenomenon has been advanced and also facilitate fuller understanding of the phenomenon for readers. Researchers recognize the story line developed based on themes as a strategy of "meaning" making, not "truth" making. ${ }^{[72,74,75]}$ If the story line is coherent and logical, readers are able to travel easily through the worlds of themes' developers and decide for themselves whether themes are legitimate research endeavours. ${ }^{[76]}$

\section{Some PRAgmatic points}

Qualitative content analysis and thematic analysis are widely recognised for being transparent and systematic in terms of research processes. As flexible research approaches, it is recommended that researchers are trained for gaining insight into the intuitive aspects of qualitative data analysis. However, without a clear understanding and unified application of the principles of data analysis, such flexibility may limit their international application across different disciplines and lead the reader to misinterpret or discredit study findings. ${ }^{\text {[77] }}$ Therefore, this paper presented an analytical overview of theme and suggested a method for theme development to address the gap in the international literature.

The main strength point of the suggested method in this study is the inclusion of creativity and the involvement of researchers' subjectivity in the different steps of theme development. Maintaining creativity along with preserving principles of data analysis is allowed. Morse (2011) believes that experienced researchers are able to make innovations and deviate from the prescribed method, but novices may be unaware of the issues raised from making these changes. ${ }^{[78]}$ This may lead to inconsistencies in methodology and threaten rigour. In this respect, there is a call for the improvement in the quality of publications with a focus on a precise description of the method applied for data analysis. ${ }^{[79]}$ An important element of such a precise description is induction, deduction and abduction processes applied to identify themes and an account of how they give a thoughtful response to the study question. ${ }^{[80,81]}$

As suggested, ensuring the development of high quality 
themes equally depends on the researchers' commitment to the collection of high quality data. For instance, if a meaningful, representative theme is not reached by using the principle of "iterative" data analysis in qualitative research, data collection should be reorganised in such a way to obtain in-depth answers, and also sufficient effort should be made in labelling themes appropriately and their integration. ${ }^{[30,82]}$ Avoiding selective analysis of data, premature closure of data analysis, being sensitive in data analysis should also be added to the above list of possible flaws in qualitative data analysis. ${ }^{[17]}$ There is also a need to adhere to the analytic framework articulated systematically from the overall research method, and concurrent data collection and analysis to develop theme. It is also critical that enough time is allocated for analysis, ambiguities are tolerated and assumptions and subjective perspectives about the topic of research are carefully articulated. ${ }^{[1,46,83]}$

\section{Conclusion}

The impact of authors' own views in this paper both in the presentation of suggested theme development method and the process of selecting relevant literature to support the phases and stages of the proposed method should be considered during the interpretation of findings. While the review is highly subjective we claim it is worthwhile to reconsider the process of thematic construction in nursing research so as to provide further discussion and debate by which to advance rigour in qualitative nursing research.

There are variations in theme development that have resulted in dissimilar levels of abstraction in the products of data analysis that may result in inconsistent implications for evidencebased practice. Using our own qualitative analysis experiences and with the support of the relevant literature, we have suggested a pragmatic and step by step method of theme development that has the capacity to support researchers and enable further understanding about how themes are developed.

Considering both objective and subjective aspects of the participants' accounts in the process of theme development, encouraging researchers' to apply creativity in the process of theme development, going through the ladder of the abstraction process step-by-step, and making a connection between developing themes and current knowledge are some of the benefits of the application of our suggested method of theme development in this paper.

The suggested method can be utilised to reduce ambiguities, improve quality and rigour of data analysis, and bring some agreement between researchers on how to judge the quality of the process of theme development. Moreover, since the findings of qualitative research offers a deeper understanding of the complexities of human experiences' at the level of implementation, the method of theme development suggested in this paper can be an effective means by which participants' experiences can inform practice development and advance the consolidation of results to form well-grounded nursing interventions.

\section{ACKNOWLEDGEMENTS}

The authors of this article sincerely thank Immy Holloway Professor Emeritus in the School of Health and Social Care at Bournemouth University, United Kingdom for her precious scientific support and editing the article.

\section{CONFlicts OF INTEREST Disclosure}

No conflict of interest has been declared by the authors.

\section{REFERENCES}

[1] Holloway I, Wheeler S. Qualitative Research in Nursing and Healthcare. Wiley-Blackwell publishing, 3th edition, Oxford, UK. 2010.

[2] Smith J, Bekker H, Cheater F. Theoretical versus pragmatic design in qualitative research. Nurse Researcher. 2011; 18(2): 39-51. PMid:21319483 http://dx.doi.org/10.7748/nr2011.01.18. 2.39.c8283

[3] Bradley EH, Curry LA, Devers KJ. Qualitative data analysis for health services research: Developing taxonomy, themes, and theory. Health Services Research. 2007; 42(4): 1758-72. PMid:17286625 http://dx.doi.org/10.1111/j.1475-6773.2006.00684.x

[4] Brod M, Tesler LE, Christensen TL. Qualitative research and content validity: developing best practices based on science and experience. Quality of Life Research. 2009; 18(9): 1263-1278. PMid:19784865 http://dx.doi.org/10.1007/s11136-009-9540-9

[5] Forman J, Damschroder L. Empirical Methods for Bioethics: A Primer. In Jacoby L and Siminoff LA (Eds.). Advances In Bioethics (Vol. 11). USA: Elsevier; 2008. 39-62.
[6] Berg KE, Latin RW. Research Methods in Health, Physical Education, Exercise Science, and Recreation (Third ed.). Baltimore, Lippincott Williams \& Wilkins; 2008

[7] Zhang Y, Wildemuth BM. Qualitative Analysis of Content. In B. Wildemuth (Ed.), Applications of Social Research Methods to Questions in Information and Library Science. Westport, CT: Libraries Unlimited. 2009.

[8] Vaismoradi M, Turunen H, Bondas T. Content analysis and thematic analysis: Implications for conducting a qualitative descriptive study. Nursing \& Health Sciences. 2013; 15(3): 398-405. PMid:23480423 http://dx.doi.org/10.1111/nhs. 12048

[9] Ayres L, Kavanaugh K, Knafl KA. Within-case and across-case approaches to qualitative data analysis. Qualitative Health Research 2003; 13(6): 871-83. http://dx.doi.org/10.1177/104973230 3013006008

[10] Sandelowski M. What's in a name? Qualitative description revisited Research in Nursing \& Health. 2010; 33(1): 77-84. PMid:20014004 
[11] Green J, et al. Generating best evidence from qualitative research: the role of data analysis. Australian and New Zealand Journal of Public Health. 2007; 31(6): 545-50. PMid:18081575 http: //dx.doi.org/10.1111/j.1753-6405.2007.00141.x

[12] Krauss SE. Research paradigms and meaning making: A primer. The Qualitative Report. 2005; 10(4): 758-770.

[13] Sandelowski M, Leeman J. Writing usable qualitative health research findings. Qualitative Health Research. 2012; 22(10): 140413. PMid:22745362 http://dx.doi.org/10.1177/104973231 2450368

[14] Schreier M. Qualitative Content Analysis in practice. London: SAGE Publications. 2012.

[15] Horsburgh D. Evaluation of qualitative research. Journal of Clinical Nursing. 2003;12(2): 307-312. http://dx.doi.org/10.1046/j $.1365-2702.2003 .00683 . \mathrm{x}$

[16] Hesse-Biber SN, Leavy P. The Practice of Qualitative Research. SAGE Publications, 2th edition, London, UK. 2011.

[17] Bazeley P. Analysing qualitative data: More than "Identifying Themes". The Malaysian Journal of Qualitative Research. 2009; 2(2): 6-22.

[18] Lapan SD, Quartaroli MT, Riemer FJ. Qualitative Research: An Introduction to Methods and Designs. Jossey-Bass publishing, 1th edition, San Francisco, USA. 2012.

[19] Ryan GW, Bernard HR. Techniques to identify themes. Field Methods. $2003 ; 15(1): 85-109$. http://dx.doi .org/10.1177/15258 22X02239569

[20] Buetow S. Thematic analysis and its reconceptualization as "saliency analysis". Journal of Health Services Research \& Policy. 2010; 15(2): 123-5. PMid:19762883 http://dx. doi.org/10.1258/jhsrp. 2 009.009081

[21] Braun V, Clarke V. Using thematic analysis in psychology. Qualitative Research in Psychology. 2006; 3(2): 77-101. http://dx.doi . org/10.1191/1478088706qp063oa

[22] Graneheim UH, Lundman B. Qualitative content analysis in nursing research: concepts, procedures and measures to achieve trustworthiness. Nurse Education Today. 2004; 24(2): 105-112. PMid:14769454 http://dx.doi.org/10.1016/j.nedt.2003.10.001

[23] Aronson J. A pragmatic view of thematic analysis. The Qualitative Report. 1994; 2(1): 1-3.

[24] Lopez KA, Willis DG. Descriptive versus interpretive phenomenology: Their contributions to nursing knowledge. Qualitative Health Research. 2004; 14(5): 726-35. PMid:15107174 http://dx.doi.o $\mathrm{rg} / 10.1177 / 1049732304263638$

[25] Morse JM. Confusing Categories and Themes. Qualitative Health Research. 2008; 18(6): 727-728.

[26] Draucker CB, Martsolf DS, Ross R, et al. Theoretical sampling and category development in grounded theory. Qualitative Health Research. 2007; 17(8): 1137-48. PMid:17928484 http://dx.doi.o $\mathrm{rg} / 10.1177 / 1049732307308450$

[27] Bailey DM, Jackson JM. Qualitative data analysis: Challenges and dilemmas related to theory and method. The American Journal of Occupational Therapy. 2003; 57(1): 57-65. http://dx.doi.org /10.5014/ajot.57.1.57

[28] Constas MA. Qualitative analysis as a public event: the documentation of category development procedures. American Educational Research Journal. 1992; 29(2): 253-266. http://dx.doi .org/10. 3102/00028312029002253

[29] Sandelowski M, Barroso J. Classifying the findings in qualitative studies. Qualitative Health Research. 2003; 13(7): 905-23. http://dx.doi.org/10.1177/1049732303253488

[30] Sandelowski M, Barroso J. Handbook for Synthesizing Qualitative Research (First ed.). New York: Springer Publishing Company. 2007.
[31] Gray JH. Densten IL. Integrating quantitative and qualitative analysis using latent and manifest variables. Quality and Quantity. 1998; 32(4): 419-31. http://dx.doi.org/10.1023/A: 1004357719066

[32] Hallberg LR. The "core category" of grounded theory: Making constant comparisons. International Journal of Qualitative Studies on Health and Well-being. 2006; 1(3): 141-148. http://dx.doi.org $/ 10.1080 / 17482620600858399$

[33] Willig C. Introducing Qualitative Research in Psychology. Open University Press, 3th edition, New York, USA. 2013.

[34] Hsieh HF, Shannon SE. Three approaches to qualitative content analysis. Qualitative Health Research. 2005; 15(9): 1277 88. PMid:16204405 http://dx.doi.org/10.1177/104973230 5276687

[35] Braun V, Clarke V. Thematic analysis- frequently asked questions. The University of Auckland. 2016. Available from: http://www.psych.auckland.ac.nz/en/about/our-resea $\mathrm{rch} / \mathrm{research}$-groups/thematic-analysis/frequently-a sked-questions-8.html

[36] Hunter A, et al. Making meaning: The creative component in qualitative research. Qualitative Health Research. 2002; 12(3): 388-98. http://dx.doi.org/10.1177/104973202129119964

[37] Thompson C, et al. Increasing the visibility of coding decisions in team-based qualitative research in nursing. International Journal of Nursing Studies. 2004; 41(1): 15-20. http://dx.doi .org/10.10 16/j.ijnurstu.2003.03.001

[38] Wolf ZR. Exploring the audit trail for qualitative investigations. Nurse Educator. 2003; 28(4): 175-178. http://dx.doi.org/10.1097 100006223-200307000-00008

[39] DeCuir-Gunby JT, Marshall PL, McCulloch AL. Developing and using a codebook for the analysis of interview data: an example from a professional development research project. Field Methods. 2011; 23(2): 136-155. http://dx.doi.org/10.1177/1525822 $\mathrm{x} 10388468$

[40] Polit DF, Beck CT. Essentials of Nursing Research-Appraising Evidence for Nursing Practice. Wolters Kluwer. 7th edition. Philadelphia, USA. 2010.

[41] Schilling J. On the pragmatics of qualitative assessment: Designing the process for content analysis. European Journal of Psychological Assessment. 2006; 22(1): 28-37. http://dx.doi.org/10.1027 /1015-5759.22.1.28

[42] Ashworth PD. The variety of qualitative research. Part two: nonpositivist approaches. Nurse Education Today. 1997; 17(3): 219-24. http://dx.doi.org/10.1016/S0260-6917 (97)80137-2

[43] Insch GS, Moore JE, Murphy LD. Content analysis in leadership research: Examples, procedures, and suggestions for future use. The Leadership Quarterly. 1997; 8(1): 1-25. http://dx.doi.org/10 1016/S1048-9843(97) 90028-X

[44] Oktay JS. Grounded Theory: Pocket Guides to Social Work Research Methods. Oxford University Press, 1th edition, New York, USA. 2012.

[45] Yin RK. Qualitative Research from Start to Finish. The Guilford Press, 2th edition, New York, USA. 2016.

[46] Birks M, Chapman Y, Francis K. Memoing in qualitative research: Probing data and processes. Journal of Research in Nursing. 2008; 13(1): 68-75. http://dx.doi.org/10.1177/1744987107081 254

[47] Rodgers BL, Cowles KV. The qualitative research audit trail: A complex collection of documentation. Research in Nursing \& Health. 1993; 16(3): 219-26. http://dx.doi.org/10.1002/nur.47701 60309

[48] Mills J, Bonner A, Francis K. Adopting a constructivist approach to grounded theory: Implications for research design. International 
Journal of Nursing Practice. 2006; 12(1): 8-13. PMid:16403191 http://dx.doi.org/10.1111/j.1440-172X.2006.00543.x

[49] Forman J, et al. Qualitative research methods: Key features and insights gained from use in infection prevention research. American Journal of Infection Control. 2008; 36(10): 764-771. PMid:18834752 http://dx.doi.org/10.1016/j.ajic.2008.03.010

[50] Gale NK, Heath G, Cameron E, et al. Using the framework method for the analysis of qualitative data in multi-disciplinary health research. BMC Medical Research Methodology. 2013; 13(117). http: //dx.doi.org/10.1186/1471-2288-13-117

[51] Bowen GA. Naturalistic inquiry and the saturation concept: a research note. Qualitative Research. 2008; 8(1): 137-152. http: //dx.doi.org/10.1177/1468794107085301

[52] Morse JM, et al. Verification strategies for establishing reliability and validity in qualitative research. International Journal for Qualitative methods. 2002; 1(2): 13-22.

[53] Glaser BG. The constant comparative method of qualitative analysis. Grounded Theory Review-An International Journal. 2008; 7(3).

[54] Frost N, et al. Pluralism in qualitative research: the impact of different researchers and qualitative approaches on the analysis of qualitative data. Qualitative Research. 2010; 10(4): 441-60. http://dx.doi.org/10.1177/1468794110366802

[55] Starks H, Trinidad SB. Choose your method: A comparison of phenomenology, discourse analysis, and grounded Theory. Qualitative Health Research. 2007; 17(10): 1372-80. PMid:18000076 http://dx.doi.org/10.1177/1049732307307031

[56] Temple B, Young A. Qualitative research and translation dilemmas. Qualitative Research. 2004; 4(2): 161-78. http://dx.doi.org/1 $0.1177 / 1468794104044430$

[57] Twinn S. An exploratory study examining the influence of translation on the validity and reliability of qualitative data in nursing research. Journal of Advanced Nursing. 1997; 26(2): 418-423. http: //dx.doi.org/10.1046/j.1365-2648.1997.1997026418.x

[58] Chen HY, Boore JRP. Translation and back-translation in qualitative nursing research: methodological review. Journal of Clinical Nursing 2010; 19(1-2): 234-39. PMid:19886874 http://dx.doi .org/10. $1111 / j .1365-2702.2009 .02896 . x$

[59] Dixon-Woods M, et al. Synthesising qualitative and quantitative evidence: a review of possible methods. Journal of Health Services Research \& Policy. 2005; 10(1): 45-53B. http://dx.doi.org/1 $0.1258 / 1355819052801804$ PMid: 15667704

[60] Regmi K, Naidoo J, Pilkington P. Understanding the processes of translation and transliteration in qualitative research. International Journal of Qualitative Methods. 2010; 9(1): 16-26.

[61] Cho J, Trent A. Validity in qualitative research revisited. Qualitative Research. 2006; 6(3): 319-340. http://dx.doi.org/10.1177/1 468794106065006

[62] Sparkes AC, Smith B. Qualitative Research Methods in Sport, Exercise and Health: From Process to product. 1th edition, Routledge publishing, New York, USA. 2014.

[63] Barnett-Page E, Thomas J. Methods for the synthesis of qualitative research: a critical review. BMC Medical Research Methodology. 2009; 9(59): 1-11. http://dx.doi.org/10.1186/1471-2288-9-59

[64] Ollerenshaw JA, Creswell JW. Narrative research: A comparison of two restorying data analysis approaches. Qualitative Inquiry. 2002; 8(3): 329-47. http://dx.doi.org/10.1177/107780040 08003008

[65] Seal C, Gobo G, Gubrium JF, et al. Qualitative Research Practice: Concise Paperback Edition. 1th edition, SAGE Publications, London, UK. 2007.
[66] Tinker C, Armstrong N. From the outside looking in: how an awareness of difference can benefit the qualitative research process. The Qualitative Report. 2008; 13(1): 53-60.

[67] Munhall PL, Chenail R. Qualitative Research Proposals and Reports: A Guide Jones \& Bartlett publishers, 3th edition, London, UK. 2008

[68] Dunne $C$. The place of the literature review in grounded theory research. International Journal of Social Research Methodology. 2011; 14(2): 111-124. http://dx.doi.org/10.1080/13645579.2010 .494930

[69] Snelgrove S. Conducting qualitative longitudinal research using interpretative phenomenological analysis. Nurse Researcher. 2014; 22(1): 20-5. PMid:25251816 http://dx . doi .org/10.7748/nr . $22.1 .20 . \mathrm{e} 1277$

[70] Koch T. Establishing rigour in qualitative research: the decision trail. Journal of Advanced Nursing. 2006; 53(1): 91-100. PMid:16422698 http://dx.doi.org/10.1111/j.1365-2648.2006.03681.x

[71] Kuper A, Reeves S, Levinson W. An introduction to reading and appraising qualitative research. BMJ. 2008; 337(a288): 404-409. http://dx.doi.org/10.1136/bmj.a288

[72] Pratt MG. From the editors: For the lack of a boilerplate: Tips on writing up (and reviewing) qualitative research. Academy of Management Journal. 2009; 52(5): 856-862. http://dx.doi .org/10. 5465/AMJ . 2009. 44632557

[73] Birks M, Mills M, Francis K, et al. A thousand words paint a picture: The use of storyline in grounded theory research. Journal of Research in Nursing. 2009; 14 (5): 405-417. http://dx. doi .org/10.1177 $/ 1744987109104675$

[74] Bailey PH, Tilley S. Storytelling and the interpretation of meaning in qualitative research. Journal of Advanced Nursing. 2002; 38(6): 574 83. http://dx.doi.org/10.1046/j.1365-2648.2000.02224 . $\mathrm{x}$

[75] O'Reilly M, Parker N. Unsatisfactory Saturation: a critical exploration of the notion of saturated sample sizes in qualitative research. Qualitative Research. 2012; 13(2): 190-197. http://dx.doi.org /10.1177/1468794112446106

[76] Koch T. Story telling: is it really research? Journal of Advanced Nursing. 1998; 28(6): 1182-90. PMid:9888361 http://dx.doi.o $\mathrm{rg} / 10.1046 / \mathrm{j} .1365-2648.1998 .00853 . \mathrm{x}$

[77] Hyett N, Kenny A, Dickson-Swift V. Methodology or method? A critical review of qualitative case study reports. International Journal of Qualitative Studies on Health and Well-being. 2014; 9(23606). http://dx.doi.org/10.3402/qhw.v9.23606

[78] Morse JM. Molding qualitative health research. Qualitative Health Research. 2011; 21(8): 1019-1021. PMid:21768617 http://dx.d oi.org/10.1177/1049732311404706

[79] Jasper M, Vaismoradi M, Bondas T, et al. Validity and reliability of the scientific review process in nursing journals - time for a rethink? Nursing Inquiry. 2014; 21(2): 92-100. PMid:23600446 http://dx.doi.org/10.1111/nin.12030

[80] Firmin MW. The SAGE encyclopaedia of qualitative research methods. Given, L. M., [General editor] London: SAGE Publications; 2008.

[81] Lipscomb M. Abductive reasoning and qualitative research. Nursing Philosophy. 2012; 13(4): 244-256. PMid:22950728 http://dx.d oi.org/10.1111/j.1466-769x.2011.00532.x

[82] Willig C. Phenomenological methods (Second ed.). London: Open University Press; 2008.

[83] Morrow S. Quality and trustworthiness in qualitative research in counselling Psychology. Journal of Counseling Psychology. 2005; 52(2): 250-60. http://dx.doi.org/10.1037/0022-0167.52.2.250 